\title{
Literature pollution: a personal experience
}

\author{
Kannan Sridharan $^{1}$ (D) - Gowri Sivaramakrishnan ${ }^{2}$
}

Received: 13 December 2016 / Accepted: 23 December 2016 / Published online: 7 January 2017

(C) Springer-Verlag Berlin Heidelberg 2017

\section{Sir,}

This letter is regarding our systematic review on the usefulness of therapeutic clowns in pediatrics published in your journal [3]. After the publication, we learned that one of the included papers was fictitious, and this was mentioned in the acknowledgement [2]. The lead author, in a personal communication, stated that the concerned study was conducted as a part of "April fool's day". Fortunately, the data from their paper was included only in one of the secondary outcome measures and exclusion of this data did not affect the results, conclusion, and validity of the review.

Papers published in top quality journals are looked upon as key source of important evidence [5]. Novel research is always recognized by reputed journals, and the ultimate reward comes in the form of publishing their data. In the era where research and publication are key components that determine our future prospects in career, lack of sufficient space has been one most common reason for refusal to publish [1]. This lack of space can also be due to publication of such fabricated papers which do not add to generating good quality evidence.
We strongly believe that this kind of "literature pollution" must not be encouraged and completely protested. As regards to our systematic review, it was a time-consuming process in going over the whole process again [4]. We believe that the journal editors of renowned journals should take steps to prevent this kind of literature pollution in the future.

\section{References}

1. Ali J (2010) Manuscript rejection: causes and remedies. Journal of Young Pharmacists : JYP 2(1):3-6

2. Alverson BK, Wilson KM, Shah SS (2013) A randomized trial of facilitated family-centered rounds. Hospital Pediatrics 3:156-161

3. Sridharan K, Sivaramakrishnan G (2016) Therapeutic clowns in pediatrics: a systematic review and meta-analysis of randomized controlled trials. Eur J Pediatr 175:1353-1360

4. Sridharan K, Sivaramakrishnan G (2017) Therapeutic clowns in pediatrics: a systematic review and meta-analysis of randomized controlled trials. Corrigendum. Eur J Pediatr. doi:10.1007/s00431-016-2832-5

5. Writing for scholarly journals. Available at: http://www.gla.ac. uk/media/media_41223_en.pdf (Accessed on 07 Dec 2016)

Communicated by Beat Steinmann

Kannan Sridharan

skannandr@gmail.com

1 Department of Health Sciences, College of Medicine, Nursing and Health Sciences, Fiji National University, Suva, Fiji

2 Department of Oral Health, College of Medicine, Nursing and Health Sciences, Fiji National University, Suva, Fiji 